\title{
Processing of unfamiliar accents in monolingual and bilingual children: effects of type and amount of accent experience
}

\author{
Helena LEVY ${ }^{1 \star}$, Lars KONIECZNY², and Adriana HANULÍKOVÁ ${ }^{2,3}$ \\ ${ }^{1}$ GRK 'Frequency effects in language', University of Freiburg, Germany, ${ }^{2}$ University of Freiburg, Germany, \\ and ${ }^{3}$ Freiburg Institute for Advanced Studies (FRIAS), Freiburg, Germany \\ ${ }^{*}$ Corresponding author. University of Freiburg, Sprachwissenschaftliches Seminar, 79085 Freiburg. \\ E-mail: helena.levy@frequenz.uni-freiburg.de
}

(Received 19 October 2017; revised 6 June 2018; accepted 31 October 2018;

first published online 8 January 2019)

\begin{abstract}
Substantial individual differences exist in regard to type and amount of experience with variable speech resulting from foreign or regional accents. Whereas prior experience helps with processing familiar accents, research on how experience with accented speech affects processing of unfamiliar accents is inconclusive, ranging from perceptual benefits to processing disadvantages. We examined how experience with accented speech modulates mono- and bilingual children's (mean age: 9;10) ease of speech comprehension for two unfamiliar accents in German, one foreign and one regional. More experience with regional accents helped children repeat sentences correctly in the regional condition and in the standard condition. More experience with foreign accents did not help in either accent condition. The results suggest that type and amount of accent experience co-determine processing ease of accented speech.
\end{abstract}

Keywords: experience with accents; regional accents; foreign accents; speech perception; school-aged children; intelligibility; bilingualism

\section{Introduction}

Many children grow up hearing different languages and various regional or foreign accents. Home language use may be limited to one language (e.g., Standard German), but globally the more frequent case is that more than one language as well as regional or foreign accents are spoken in the family (Grosjean, 2010). The type of variation children experience and how frequently they are exposed to variable speech differs considerably across families. In the present study, we examine the effects of experience with variable native and non-native speech on children's processing of unfamiliar accents. More specifically, we examine how monolingual and bilingual children process an unfamiliar regional and foreign accent depending on the type and amount of accent experience. ${ }^{1}$

\footnotetext{
${ }^{1}$ For a critical evaluation of the terms 'native speaker', 'monolingual speaker', and 'bilingual speaker', see Davies (2003), Dewaele (2018), and Grosjean (2010).

(C) The Author(s), 2019. Published by Cambridge University Press. This is an Open Access article, distributed under the terms of the Creative Commons Attribution licence (http://creativecommons.org/licenses/by/4.0/), which permits unrestricted re-use, distribution, and reproduction in any medium, provided the original work is properly cited.
} 
Monolingual children are defined here as those children who grew up understanding and speaking a German local variety (up to the age of six, when some of them might have been enrolled in foreign language courses at school). Bilingual children are defined here as those who understand or speak one or more language(s) other than German and started learning German before the age of six.

\section{Experiential factors in the processing of accented speech}

We know from previous studies that both adults (Bradlow \& Bent, 2008) and children (Bent, 2014; Bent \& Atagi, 2015) have greater difficulty recognizing words in accented speech than in unaccented speech. For adults and children alike, the impact of these perceptual difficulties is lowered by experience with a particular accent over a long period of time (adults: Hanulíková \& Weber, 2012; Porretta, Tucker, \& Järvikivi, 2016; Sumner \& Samuel 2009; Witteman, Weber, \& McQueen, 2013; children: Floccia, Delle Luche, Durrant, Butler, \& Goslin, 2012; Kitamura, Panneton, \& Best, 2013; Leung, 2012) or after short-term exposure (adults: Clarke \& Garrett, 2004; Maye, Aslin, \& Tannenhaus, 2008; children: Schmale, Cristia, \& Seidl, 2012; Van Heugten \& Johnson, 2014). When we hear a word produced in a familiar accent, acoustic-phonetic cues normally conform to this word's mental representation, which is formed by previously encountered versions of this word, and thus word recognition usually succeeds.

Prior accent exposure to familiar accents or short-term adaptation to accents thus results in clear processing advantages. However, it is less conclusive whether experience with accented speech also helps listeners process unfamiliar accents. In order to understand spoken language in an unfamiliar accent, listeners need to be able to match the accented word form with an existing lexical representation. If the acoustic signal deviates from the previously encountered versions of this word, it may take longer to access the intended word (Bent \& Atagi, 2015). However, exposure to systematic variability can help listeners to generalize adaptation to foreign-accented speech across unfamiliar talkers (Sidaras, Alexander, \& Nygaard, 2009), unfamiliar accents in native listening (Baese-Berk, Bradlow, \& Wright, 2013) and non-native listening (Bent \& Bradlow, 2003), and across languages (Reinisch, Weber, \& Mitterer, 2013). Most of these studies test the intelligibility of foreignaccented speech, with intelligibility being defined as the extent to which a listener understood an utterance, typically assessed by asking participants to repeat back or transcribe what they heard (Munro \& Derwing, 1999). Baese-Berk et al. (2013) showed that intelligibility of a novel talker increased for a familiar accent (Mandarin Chinese) after training with a single foreign accent (Mandarin Chinese) as well as with multiple foreign accents. However, intelligibility performance increased for a novel talker with an unfamiliar accent only in the multiple-foreign-accent training group. The authors suggest that non-native speakers share some common features in their production, resulting from similar production difficulties for a given language, as well as general non-native features such as lower speaking rate. Such commonalities across accents then result in systematic variability across different accents and lead to processing benefits.

Some studies, however, question such advantages for native as well as for non-native listeners (e.g., Algethami, Ingram, \& Nguyen 2010; Major, Fitzmaurice, Bunta, \& Balasubramanian, 2002; Munro, Derwing, \& Morton, 2006; Stibbard \& Lee 2006; Tao \& Taft, 2016). Tao and Taft (2016) examined how different home language 
settings affect perception of unfamiliar accents. Young adults from different home language environments (native English speakers, heritage language speakers mostly communicating in a language other than English, and mixed language speakers communicating in another language and in English with a foreign accent) were compared in their performance in an accented sentence transcription task with unfamiliar foreign accents. Heritage language speakers and mixed language speakers both performed worse than native English speakers but there was no significant difference between heritage and mixed language speakers. The authors conclude that listeners who have a lot of experience with foreign-accented speech do not have an advantage when processing an unfamiliar accent compared to listeners with less experience with foreign-accented speech. Tao and Taft measured experience with accented speech in a retrospective self-report, focusing on the language environment in the adult participants' childhood homes. The influence of accent experience on the perception of unfamiliar accents, though, might be more accurately revealed in subjects who are living in diverse language and accent environments at the time of testing, in order to better capture how variable input impacts accent processing. Following Floccia et al. (2012), experience with accents cannot be captured by looking only at the home language environment but should also take into account accents spoken in the wider surroundings including school, friends, and free-time activities.

\section{The processing of accented speech in early childhood}

When it comes to children, most studies have shown that accent or speaker variation during short-term training procedures can improve the acquisition of words (Rost \& McMurray, 2009; Schmale, Hollich, \& Seidl, 2011). In terms of word recognition, Potter and Safran (2017) showed that American English infants aged 1;6 could better understand an unfamiliar British English accent after being exposed to multiple unfamiliar accents (Australian, Southern American English, Indian) but not after being exposed to multiple talkers of only one unfamiliar accent. This suggests that variability in the input can lead to a processing advantage for unfamiliarly accented speech (in line with results from adult literature, see Baese-Berk et al., 2013). However, other studies have shown that three- to five-year-old children were slower and made more errors pointing at creatures on a screen when they had learned their names in two artificial accent variants as compared to only one (Creel, 2014). Instead of generalizing over the partial matches such as alternations between $/ \mathrm{I} /$ and /i:/ and ignoring inconsistencies, Creel suggested that children encode two separate variants of these words or create less stable entries (see also Rost \& McMurray, 2009). Similarly, a study with monodialectal and multidialectal children suggests that long-term accent experience has a destabilizing influence on lexical representations. Durrant, Delle Luche, Cattani, and Floccia (2015) showed in an intermodal preferential looking procedure that multidialectal infants looked longer at targets following naming, independent of whether the word was correctly produced or mispronounced, whereas monodialectal infants looked longer at targets only after the correct pronunciation. This suggests that the multidialectal infants' representations differ from those of their monodialectal peers, possibly due to more experience with variable input. The authors suggest that multidialectal infants' representations are less stable than those of monodialectal infants and that this might lead to a disadvantage in their ability to detect mispronunciations. However, studies with adult 
participants suggest that accepting mispronunciations may not reflect a failure in acoustic-phonetic processing but can be a useful adaptation strategy in bilinguals who are often exposed to accented speech (Samuel \& Larraza, 2015). The costs and benefits of exposure to multiple varieties are discussed by Clopper (2014). According to Clopper, experience with more than one variety can lead to a processing advantage for both varieties due to an increased flexibility in mapping a perceived word form onto variable representations: "a given stimulus can be mapped onto more than one linguistic representation, which increases the likelihood that the stimulus will be accurately identified" (Clopper, 2014, p. 80). On the other hand, competition between lexical representations is increased, which can lead to less stable lexical representations and thus to processing costs (p. 81). Thus it seems that successful comprehension of accented speech requires distinctive phonological categories as well as stable and flexible lexical representations (Best, Tyler, \& Quann, 2009; Creel, 2012; Cristia, Seidl, Vaughn, Schmale, Bradlow, \& Floccia, 2012).

Taken together, there seems to be a discrepancy between studies showing that infants profit from previous accent exposure when processing an unfamiliar accent, while school children do not. One probable source for this inconsistency is that the tasks used vary depending on the age of the children. Lalonde and Holt (2016) point out that age-inappropriate tasks are often used for school-aged children, resulting in spurious differences between children and adults as well as between children and toddlers or infants. Infants, who have limited cognitive and linguistic abilities, are often tested in closed-set tasks such as preferential looking or headturn paradigm. These tasks are cognitively less demanding (Bent \& Atagi, 2015). In contrast, older children and adults are usually tested in open-set tasks that often assess comprehension using speech production, as in word-repetition and definition tasks. Certain variables such as talker variability have been shown to have stronger effects in open-set tasks as compared to closed-set tasks (Clopper, Pisoni, \& Tierney, 2006), leading to differences between children and infants (Bent \& Atagi, 2015). Taken together, incongruous results between studies may reflect differing task demands for various age groups (Harte, Oliveira, Frizelle, \& Gibbon, 2016).

\section{The role of age}

Studies with school-aged children have shown that the ability to comprehend an unfamiliar accent is still developing between the ages of four and seven (Nathan, Wells, \& Donlan, 1998), possibly as a result of a smaller vocabulary and, importantly, of less experience with varying word forms. This means that children's perceptual processing abilities are still developing during the primary-school years and that their comprehension of unfamiliar accents is imperfect. From a developmental perspective on accent processing, this makes school-aged children a very interesting age group to examine. However, as pointed out by several researchers (Cristia et al., 2012), most studies focus on adults and infants, and the few studies on school-aged children's processing of accented speech are inconclusive. At the age of twelve, perceptual learning tested via lexically guided retuning of consonants appears to be adult-like (McQueen, Tyler, \& Cutler, 2012), while perceptual flexibility tested via an intelligibility task with an unfamiliar accent appears not to be adult-like (Bent, 2015). Most of the children in Bent's study, however, did not have any experience with foreign-accented speech. Apart from experience with accented speech, additional factors exist that may help children to process unfamiliar accents: among others, 
vocabulary size (Bent, Baese-Berk, Borrie, \& McKee, 2016), working memory, and executive functions (Bent, 2015), as well as lexical frequency (Bent, 2014). Perception under other types of adverse listening conditions such as noise or reverberation does not reach adult-like competence until the age of thirteen years and older (Johnson, 2000), and nine-year olds show decrements compared to adult listeners at word recognition under high variability conditions (Jacewicz \& Fox, 2014). Furthermore, five- to eight-year-old children show greater decrements at word recognition in foreign-accented speech compared to adults (Bent \& Atagi, 2017), suggesting that phonological processing skills are not fully developed in the early school years.

\section{Experience with more than one language}

In addition to experience with accented speech, and factors such as cognitive skills and language proficiency, knowledge of additional languages and varieties can modulate processing ease. Previous studies suggest that bilingual children may have an advantage at processing unfamiliar accents because of their greater flexibility at mapping variable input onto mental representations, and their ability to deal with the phonology of two languages with different phonetic boundaries (Barry, 1974; Flege, Munro, \& Fox, 1994; Muench, 2011). Muench (2011, p. 2) points out that bilinguals "may be more likely to detect subtle pronunciation cues that could help them to differentiate between words" and that this ability would be crucial for processing an unfamiliar accent. Matching new sounds to familiar words requires strategies that could profit from bilingual children's exposure to greater acoustic variability and from abilities like cognitive control, which lead to improved pattern recognition (Bialystok, 2001). Results of the few studies that compare accent processing in monolingual and bilingual children are inconclusive. Evans and Lourido (in press) found that five- to six-year-old bilinguals outperform their monolingual peers at accent categorization, but they did not find a difference between monolingual and bilingual children's comprehension of unfamiliar accents. However, bilingual children's vocabulary size (when tested in one language only) has been shown to be smaller than monolinguals' (Bialystok, Luk, Peets, \& Yang, 2010), and their lexical representations might be less stable, at least if they are exposed to the language under investigation less frequently than their monolingual peers (Bosch \& Sebastián-Gallés, 2003; Ramon-Casas, Swingley, Sebastián-Gallés, \& Bosch, 2009).

\section{The present study}

Taken together, prior studies are inconclusive with respect to how exposure to different accents and languages may benefit the processing of unfamiliar accents. The aim of this study is to further clarify the role of exposure to variable speech and how it impacts monolingual and bilingual children. Here we examine this issue by testing intelligibility of foreign- and regional-accented speech in eight- to eleven-year-old children who all have experience with regional and foreign accents. We assess monolingual and bilingual children's amount of experience with accented speech and varieties using parental questionnaires, and take into account further factors such as vocabulary size and working memory.

Great variability in experience between children and a lack of objective measurement methods make it a challenge to include accent experience as a continuous variable. Most studies have operationalized experience as a binary variable and only a few have 
attempted to quantify accent experience. One such recent exception is a study by Porretta et al. (2016), who measured subjects' experience with foreign accents on a scale of 0 to 10 (based on self-reports), depending on how often they interacted with non-native speakers of English on a weekly basis $(0=$ never, $10=$ daily $)$ and to what percentage these encounters included Chinese-accented English. Their results show that strength of lexical activation and speed of word recognition in priming and visual world eye-tracking tasks using Chinese-accented English improved in a gradient way with participants' greater experience with Chinese-accented English. In the present study we attempt to operationalize amount of experience as a continuous variable, going one step further than Porretta et al. by assessing not only the regularity of encountering accented speech but also the amount of usage of accented speech in a more detailed way. We apply a fine-grained scale for measuring experience based on parental information, counting the amount of time each subject spends with different languages and with foreign- or regional-accented speech, quantifying each participant's weekly exposure to different languages and to accented speech as a percentage. Despite certain shortcomings that parental/subjective questionnaires might have, we expect this method to provide a more specific answer to the question of whether the amount of experience with accented speech matters in the comprehension of unfamiliar accents.

An additional aim of our study is to assess how the processing of foreign- and regional-accented speech is modulated by type of accent exposure. Regional and standard accents usually differ in segmental features such as deviations in vowels (Adank, van Hout, \& van de Velde, 2007) and a limited number of consonants (Mattheier, 1990; Wells, 1982), as well as suprasegmental features such as intonation (Grabe, Post, Nolan, \& Farrar, 2000; Truckenbrodt, 2002) but also syllable structure. In contrast, non-native speech usually shows larger variation at the segmental and suprasegmental level (Sereno, Lammers, \& Jongman, 2016). Depending on the source language of the non-native speaker and their L2 language proficiency, the target language syllable structure and its realization is often affected as well (e.g., vowel insertion, segment elision, lexical stress). This variation is the result of the interaction between the L1 and L2 of the speaker and leads to more between as well as within talker variability than native speech varieties (Hanulíková \& Weber, 2012). In studies that compare the processing ease of regional and foreign accents, foreign accents are usually less intelligible than regional accents (Adank, Evans, Stuart-Smith, \& Scotti, 2009; Bent et al., 2016; Floccia, Goslin, Girard, \& Konopczynski, 2006; Pinet, Iverson, \& Huckvale, 2011). However, processing ease of regional and foreign accents also depends on factors such as the speaking rate and proficiency of non-native talkers as well as on deviation from a standard or a familiar accent (cf. discussion in Floccia, Butler, Girard, \& Goslin, 2009a, and Floccia, Butler, Goslin, \& Ellis, 2009b). Furthermore, the processing of unfamiliar regional and unfamiliar foreign accents might depend on experience with regional and foreign accents.

So the questions remain: Is intelligibility of an unfamiliar accent modulated by the type and amount of accent experience? And does experience with accented speech equally affect monolingual and bilingual children?

Based on previous studies, we can formulate the following predictions about the effects of accent experience and between monolingual and bilingual children. According to exposure-to-systematic-variability accounts (e.g., Baese-Berk et al., 2013, Bent \& Bradlow, 2003), an unfamiliar accent will be more intelligible for listeners with more accent experience than for listeners with less accent experience. On the 
other hand, destabilization accounts (e.g. Tao \& Taft, 2016) predict that children with more accent experience would perform worse than children with less accent experience due to their less stable representations. We hypothesize that experience with foreignaccented speech will be beneficial for processing an unfamiliar foreign accent due to shared features between all foreign accents. Experience with regional-accented speech will be beneficial for regional accent processing.

If the stability of representations is influenced by exposure to language variability (e.g., Durrant et al., 2015), there should be overall stronger decrements in the bilingual listeners' performance compared to monolinguals, because the bilingual children are exposed to the highest degree of variability (two languages as well as regional and foreign accents). Bilingual children also have less experience with German, the target language of our study, than their monolingual peers; smaller vocabulary size could prove to be a disadvantage to them when perceiving unfamiliar accents (e.g., Bent, 2014). For our study, we thus predict that monolingual children (i.e., those with less or no experience with other languages) will perform better than bilingual children (i.e., those children with more experience with other languages) because they have heard German more often than bilinguals (who also spend time with their other language(s)) and therefore might have formed more stable lexical categories. It is unclear whether accent experience will affect monolingual and bilingual children differently, as factors such as vocabulary size might also impact accent processing in such a way that greater vocabulary size should generally lead to better performance.

\section{Method}

\section{Participants}

Thirty-three monolinguals ( 17 female) and twenty-seven bilinguals ( 17 female) between the ages of $8 ; 2$ and 11;9 (average $=9 ; 10$, years; months) participated in the experiment. Monolinguals were on average aged 9;9 $(\mathrm{SD}=10.26)$, and bilinguals were aged 9;11 $(\mathrm{SD}=8.39)$. All participants were born in Germany and were students in a school in southern Germany, in a rural region of Baden-Württemberg, where the local variety spoken by the majority of the population is Swabian (Ammon \& Loewer, 1977).

Most of the children had lived exclusively in this region $(n=57)$. Children who were born in another region of Germany (Bavaria, $n=2$; Saxony, $n=1$ ) had spent their entire school time in this region. Five additional bilingual children were tested but not included in the final analysis because they were born outside Germany and had moved to Germany at the age of three $(n=1)$, four $(n=2)$, six $(n=1)$. and nine $(\mathrm{n}=1)$. All children had substantial experience with Standard German (if not from listening to their parents then from listening to teachers and TV programs). None of the children had any experience with Palatinate- or Korean-accented German, which were the two accents tested in the comprehension task, and none of them correctly identified the accents. The bilingual children had various language backgrounds (Russian: $n=9$, Turkish: $n=5$, Albanian: $n=3$, Serbian: $n=2$, other languages: Portuguese, Spanish, Greek, Ewe, Arabic, Urdu, Croatian, Italian).

\section{Stimuli}

Stimuli included 36 German meaningless sentences (e.g., das Bild gibt dem Jungen einen Stuhl 'the picture gives the boy a chair'; see 'Appendix' for a full list of sentences). We 
used syntactically correct but semantically anomalous and unpredictable sentences to minimize the contribution of contextual knowledge to intelligibility (e.g., Davis, Johnsrude, Hervais-Adelman, Taylor, \& McGettigan, 2005). If the meaning of individual keywords cannot be inferred from sentential context, listeners have to attend better to phonological cues and to pronunciation. Intelligibility of accented sentences is weaker in semantically unpredictable contexts (Behrman \& Akhund, 2013), and thus ceiling effects can be minimized.

Each sentence contained three to four keywords (e.g., picture, gives, boy, chair in the sentence above). Keywords were selected from the 'childlex' corpus (Schroeder, Würzner, Heister, Geyken, \& Kliegl, 2015), which lists 10 million words from over 500 children's books specifically for six- to twelve-year-olds. For the construction of the sentences, high-frequency keywords (normalized lemma frequency of 100 and higher per million) and low-frequency keywords (normalized lemma frequency of 25 and lower) were chosen from the corpus such that there was an approximately equal number of high- and low-frequency words across the sentences.

Sentences were recorded with three female speakers, each representing one specific accent (similar to previous studies, e.g., Bent, 2018; Bent \& Atagi, 2015; Tao \& Taft, 2016). Hearing one single speaker per accent condition allowed children to adapt to this specific speaker. There was one speaker with a Standard German accent. Standard German is defined here as the pronunciation based on model speakers in the national media (Ammon, 2015). One speaker was from South Korea, speaking Korean-accented German, who had been in Germany for five years at the time of recording and had learned German at a language school for two years. The third speaker was from the Rhineland-Palatinate region in Germany and was a proficient user of the Palatinate German variety. We asked her to speak with a Palatinate German accent. We are using the term 'accent' here to refer to her pronunciation because the speaker did not change the syntax or vocabulary of the sentences. Palatinate is a regional German variety, which differs from Standard German not only phonologically but also syntactically and lexically. Importantly, Palatinate German pronunciation also differs from the Swabian pronunciation of our test region in several features (e.g., the typical palatalizations of Palatinate German do not occur in Swabian: Tag 'day', pronounced as /ta:k/ in Standard German is /da: $\chi$ / in Palatinate German and /da:k/ in Swabian; morgen 'tomorrow'/møвgn/ in Standard German, is /məjə/ in Palatianate and /morgə/ in Swabian).

Stimuli were recorded in a soundproof booth with an AKG C2000B-microphone at a sampling rate of $48 \mathrm{kHz}$. The speakers were instructed to read each sentence, memorize it, and then articulate it in a way that seemed natural to them. The regional accent speaker was asked not to adapt the grammar or vocabulary of the sentences to her dialect. The mean duration of utterances produced by the regional accent speaker was $1600 \mathrm{~ms}(\mathrm{SD}=369)$, by the standard speaker $2040 \mathrm{~ms}(\mathrm{SD}=315)$, and by the foreign accent speaker $2220 \mathrm{~ms}(\mathrm{SD}=430)$. Utterances produced by the regional accent speaker were significantly shorter than those by the Standard German speaker or the foreign accent speaker (both $p s<.001$ ), whereas sentence duration in the foreign accent did not significantly differ from Standard German $(p>.1)$. The Palatinate German accent differed from Standard German, e.g., in the following features: /ə/ in the offset was replaced by /I/ (e.g., seltsame/zeltza:mə/ 'strange'), /ç/ was palatalized to / $/$ / (e.g., Mädchen /me:tçən/ 'girl'), /b/ was replaced by /v/ (e.g., graben /gra:bn/ 'to dig'), /av/ was monophtongized to /o/ (e.g., as in blaue /blavə/ 'blue'), and palatalization of /pf/ to /p/ (e.g., Pfanne /pfanə/ 'pan'). Note that none of 
these features occur in Swabian. The Korean accent differed from Standard German in several features: there were insertions (e.g., schnüffelnder / $\mathrm{n}$ Yflnde/ 'sniffing' was pronounced as / nnyfələnde/), palatalizations (e.g., Buch /bu: $\chi /$ 'book', pronounced as /bu:k/), and affricate replacements (e.g., Zopf/tsopf/ 'braid' produced as /topf/), as well as other consonant and vowel changes. We applied a Levenshtein algorithm (Levenshtein, 1966; see also Heeringa, 2004) to determine the distances between regional and standard stimuli, and between foreign and standard stimuli. We followed Pettersson, Megyesi, and Nivre's (2013) suggestion to assign weights to deviating segments, which was done here in the following way: a vowel substituted by another vowel was assigned a penalty of 0.5 ; a consonant substituted by another consonant was penalized by 0.75 , insertions by 1 , and all other penalties (deletions, vowel to consonant, consonant to vowel) by 0.4 . Another penalty was added if the length of the word changed. The regional-accented stimuli deviated more strongly from their standard counterparts than the foreign-accented stimuli $(t=1.81, p=.04)$.

Prior to the recordings, five adult German native listeners assessed the foreign and regional talkers' intelligibility and comprehensibility. They transcribed five stimulus sentences per speaker after listening to each sentence once. There was no significant difference in intelligibility between the two speakers (percentage of mistakes in transcribed keywords: Palatinate speaker $=20 \%$, Korean speaker $=18 \%, p>.1)$. We used a 9-point scale (with 1 being very comprehensible and 9 being not comprehensible at all) to assess comprehensibility. Both accent speakers were rated as equally comprehensible (mean $=5.6$ for both speakers).

\section{Procedure}

Subjects' experience with languages and accents was assessed via a parental questionnaire prior to testing. A main criterion was the number of hours per week each child spends with (a) Standard German, (b) languages other than German, (c) regional-accented German, and (d) foreign-accented German in order to find out how much experience children had with their various languages and accents. We asked parents to indicate how many hours per week their child spends with each parent, with other adults, with relatives, with friends, at school, at free-time activities, and with media or on the phone, as well as which language or accent they are exposed to within these specific time periods. Experience with accents (regional/ foreign) and experience with other languages was operationalized as a continuous variable, using the number of hours each child is exposed to different accents. We calculated a percentage value of the entire number of waking hours spent with each accent for each child as indicated by its parents (see Table 1). For 'exposure to regional accents', for example, we calculated the hours the child spends with regional accents according to the number of hours per week spent with persons speaking a regional German accent (parents, caretakers, relatives, other adults, friends, teachers, people met in free-time activities, and also time spent on the phone or on Skype talking to persons who have a regional accent). School-time was usually indicated by parents as time spent with Standard German (not with a regional accent), but as so many of the children and even some of the teachers speak with the regional Swabian dialect, we also used a teacher questionnaire where teachers indicated their own accent used in interaction with the children. For children in classes with a teacher who indicated a regional accent, school-time was then calculated as time spent with a regional accent (at this age and at the school of the participants, children usually 
Table 1. Amount of Weekly Exposure to German, Regionally and Foreign Accented German, and to Other Languages for Monolingual and Bilingual Children according to the Parental Questionnaire

\begin{tabular}{|c|c|c|c|c|c|c|}
\hline & \multicolumn{3}{|c|}{ Monolinguals $(n=33)$} & \multicolumn{3}{|c|}{ Bilinguals $(n=27)$} \\
\hline & median & $\min$ & $\max$ & median & $\min$ & $\max$ \\
\hline Weekly exposure to Standard German (\%) & 30.0 & 0 & 88.5 & 29.0 & 6.4 & 74.1 \\
\hline Weekly exposure to regional accents (\%) & 62.0 & 9.9 & 93.4 & 10.5 & 0 & 46.6 \\
\hline Weekly exposure to foreign accents (\%) & 4.1 & 0 & 32.5 & 15.4 & 0 & 74.4 \\
\hline Weekly exposure to other languages (\%) & 0 & 0 & 10.4 & 26.6 & 5.7 & 71 \\
\hline
\end{tabular}

spend almost all their school hours with one main teacher). Only one teacher reported using Swabian during interactions with children in class. Experience with regional accents was then calculated as a percentage value using the ratio of hours spent with people with a regional accent to the total number of hours as indicated by the parents. The same was done with the variables 'experience with foreign accents' and 'experience with other languages'.

For each subject, we thus had a value each for experience with regional accents and experience with foreign accents, as well as for experience with other languages. Monolingual children had no experience with other languages, with the exception of one child who, according to the questionnaire, did not understand other languages but heard other languages spoken by others at the daycare center. All bilingual children were reported to understand at least one language other than German, but the amount of input in each language varied. There was one child with only $5.7 \%$ 'other language'-input, but parents reported that she understood Arabic.

Several days before testing, the participants completed an informed consent form. Subjects were tested one by one in a quiet classroom in their primary school. Prior to the sentence repetition task, all children completed hearing screening and working memory and vocabulary assessments. Each child received a $€ 5$ voucher.

\section{Hearing screening, working memory, and vocabulary tests}

All children had normal hearing as evidenced by a pure tone hearing screening ( $25 \mathrm{~dB}$ $\mathrm{HL}$ at 500, 1000, 2000, and $4000 \mathrm{~Hz}$, and $30 \mathrm{~dB} \mathrm{HL}$ at $250 \mathrm{~Hz}$ ). To measure individual working memory capacity, we used an auditory digit span task with backward recall (using number sequences from 'HASE Heidelberger Auditives Screening'; Schöler \& Brunner, 2008). Working memory was tested because the perception task required memorization of sentences in order to repeat them. Participants were tested on sequences of three to six digits, which were presented auditorily and had to be repeated. Four out of the nine trials had to be repeated in reverse order. Individual performance was determined by computing the proportion of correctly recalled digit sequences. Vocabulary was measured using the vocabulary subpart of the Cito language test (Cito Sprachtest, 2015) but with an active instead of a passive picture naming task. For the vocabulary task, a missing or an incorrect picture naming counted as an error. Results of the vocabulary and the working memory test for monolinguals and bilinguals are displayed in Table 2. As can be seen in the table, bilingual children performed significantly worse than monolingual children in the 
Table 2. Vocabulary Size and Working Memory by Percent Correct for All Children and for Monolingual and Bilingual Children Separately. Standard Deviations Are Provided in Parentheses

\begin{tabular}{lcccc}
\hline & All children & Monolinguals & Bilinguals & $\begin{array}{c}t \text {-test (monolinguals } \\
\text { vs. bilinguals) }\end{array}$ \\
\hline $\begin{array}{c}\text { Vocabulary } \\
(\% \text { correct) }\end{array}$ & $87.67(12.92)$ & $93.45(8.41)$ & $80.49(13.95)$ & $t=8.78^{\star \star *}$ \\
\hline $\begin{array}{c}\text { Working memory } \\
(\% \text { correct) }\end{array}$ & $54.07(14.82)$ & $55.89(14.56)$ & $48.14(15.1)$ & $t=1.59$ \\
\hline
\end{tabular}

Note. ${ }^{\star * \star} \mathrm{p}<.001$.

vocabulary task, and the two groups of children were comparable in the working memory task.

\section{Sentence repetition task}

Each subject heard three blocks with 12 sentences per block. The first block of sentences was presented in the Standard German accent, the second one in the Korean accent (foreign accent condition), and the third one in the Palatinate accent (regional accent condition). We presumed that it would be helpful for children's motivation to get used to the task first by hearing the standard speaker and then the two more difficult accent speakers; therefore, the presentation order was fixed. In total, there were three experimental lists, each containing three blocks with 12 sentences in each. Subjects were randomly assigned to one of the three lists so that each subject heard each block in one of the three accents. Sentences within a block were presented in a random order, using the experimental software 'Open Sesame' (Mathôt, Schreij, \& Theeuwes, 2012). Stimuli were presented using Macbook Pro speakers at approximately $67 \mathrm{~dB}$ A (measured using an iPhone with a decibel meter app held up at the approximate position of the participant's ear; Schäfer, 2016). Participants' sentence repetitions were recorded and transcribed online by a research assistant as well as offline by a second research assistant. Each accent block started with two practice sentences, and feedback was only provided in terms of task explanation. We reminded children to start speaking only after the whole utterance was presented. We asked them not to imitate the speaker but to repeat what they understood in the way that they would normally pronounce it. No further feedback was provided. In order to stimulate the children's motivation, the sentences were presented in the format of a short video clip featuring a pirate with hearing problems, whom the child was asked to help by repeating the auditory sentences. The test sessions lasted approximately 45 minutes per subject including the assessment tests.

\section{Coding and analysis}

Responses were scored by two raters for keyword accuracy in a binary fashion, as either correct or incorrect (with an inter-rater reliability of $95 \%$; the remaining $5 \%$ were discussed until consensus was reached). Missing or incorrectly repeated keywords counted as errors. Words that deviated clearly from both the standard and the accented pronunciation in the two accent conditions (e.g., due to added or deleted morphemes such as Stacheln 'prickles' for stachelig 'prickly') were counted as errors. A plural form of a singular target word was not marked as an error as long as the 
sentence was still grammatical. Imitations of accented target words were not counted as errors (e.g., when the regional speaker produced the word Ente 'duck', as Ent and a child repeated this word as Ent).

Logistic mixed effects regression models were run using the function glmer() from the R (R Core Team, 2017) packages 'Ime4' (Bates, Maechler, Bolker, \& Walker, 2017) and 'lmerTest' (Kuznetsova, Brockhoff, \& Christensen 2015). This function fits generalized linear models with fixed and random effects and returns estimates as log odds (predicted probabilities). The dependent variable was whether or not a mistake was made when repeating keywords. We used sum coding, which means that the estimates in the following tables are in contrast to the grand mean and not to a reference condition. The models included fixed factors (EXPERIENCE WITH OTHER LANGUAGES, REGIONAL ACCENT EXPERIENCE, FOREIGN ACCENT EXPERIENCE, VOCABULARY MISTAKES (percentage of mistakes for the vocabulary task), and LEXICAL FREQUENCY), as well as random intercepts for subject and sentence to account for inter-subject and inter-sentence variability. We were mainly interested in the effects of accent experience but wanted to account for vocabulary size and word frequency. The model also included a random slope for vocabulary mistakes by items (sentence), because better vocabulary knowledge might contribute to better comprehension of certain sentences. We use sentence instead of words in the slope to account for lexical processing within sentences rather than for individual keywords. As all of the subjects had at least some experience with both regional and foreign accents, we were interested in the interaction between the two predictors EXPERIENCE WITH REGIONAL ACCENTS and EXPERIENCE WITH FOREIGN ACCENTS, as well as in the interaction between experience with the two accent types and EXPERIENCE WITH OTHER LANGUAGES.

The study was aimed at answering the question whether experience with regional or foreign accents helps monolingual and bilingual children to understand unfamiliar accents. Instead of a binary distinction between monolingual and bilingual children we used a continuous variable assessing experience with other languages. We used three models with the same predictors (one model for each accent condition) because including accent condition as a predictor led to convergence problems. The standard condition was used as a control condition. Since separate models for the three conditions were conducted, the analysis of the standard condition did not interfere with the regressions for the accented conditions.

All predictors were $z$-standardized (group mean centered) before running the models. In order to find the model of best fit, we aimed for the largest model that would still converge (Barr, Levy, Scheepers, \& Tily, 2013) and excluded unnecessary predictors on the basis of model comparisons using the function anova, which tests the models against one another ( $\mathrm{R}$ 'stats' package; $\mathrm{R}$ Core Team, 2017). The predictors VOCABULARY MISTAKES and LEXICAL FREQUENCY improved the model significantly. Working memory (assessed via digit recall), age, the children's own accents, and the specific language background of the bilingual children (all assessed via parental questionnaire) were not included in the model because they did not improve the model significantly and did not have any significant effects on accent comprehension.

\section{Results}

As can be seen in Table 3, all children performed well in the standard condition, and performance dropped in both accent conditions, with the regional accent condition 
Table 3. Percent Correct for the Three Experimental Conditions across All Children and Separately for Monolinguals and Bilinguals. Standard Deviations Are in Parentheses

\begin{tabular}{llcr}
\hline Condition & All children & Monolinguals & Bilinguals \\
\hline Standard & $96.16(5.5)$ & $97.75(3.37)$ & $94.2(6.89)$ \\
\hline Regional & $67.33(10.25)$ & $72.26(8.13)$ & $61.31(9.42)$ \\
\hline Foreign & $76.22(9.25)$ & $77.62(9.5)$ & $74.51(8.82)$ \\
\hline
\end{tabular}

showing the worst intelligibility. Overall, monolingual children performed better than bilingual children, and the difference between the two groups was descriptively larger in the regional accent condition (10.95 percentage point increase for monolinguals) than in the standard (3.55 points) and foreign accent condition (3.11 points). ${ }^{2}$

In order to analyze how accent experience influences processing in monolingual and bilingual children and in the different accent conditions, we ran three mixed effects models, one for each condition in the experiment (standard, regional, foreign). Results from the mixed effects models (see Table 4) are described separately below, first in terms of the influence of accent experience and then for the factors vocabulary size and keyword frequency.

\section{Accent experience}

As can be seen in Table 4, there was an effect of regional accent experience on comprehension in the standard and unfamiliar regional accent condition. This suggests that children benefit from experience with regional accents when processing regional-accented German as well as Standard German. All children performed well in the standard condition, confirming that mistakes in the accent conditions were due to difficulties with the specific accents. The more experience they had with regional accents, the better they understood the unfamiliar regional accent. Experience with foreign accents and experience with other languages, however, was not helpful in any condition. The interaction between experience with regional and foreign accents was included in order to examine how experience with both regional and foreign accents affects the comprehension of unfamiliar accents. There was no significant interaction in any condition. Two simplified models, one including only the variables EXPERIENCE WITH REGIONAL ACCENTS and EXPERIENCE WITH OTHER LANGUAGES, the other only EXPERIENCE WITH FOREIGN ACCENTS and EXPERIENCE WITH OTHER LANGUAGES yielded similar results. Anova model comparison showed that the larger model was the better one in all three conditions.

\footnotetext{
${ }^{2}$ As suggested by a reviewer, we compared performance of the monolingual and bilingual children in the three conditions. We ran post-hoc simplified models with only the binary predictor 'language background' [glmer (mistakes $\sim$ language_background $+(1 \mid$ subject $)+(1 \mid$ sentence $)]$. These models predicted significantly more mistakes in bilingual children than in monolingual children in the standard condition $\left(\beta=1.03, \mathrm{SE}=.38, z=2.71^{* *}\right)$ and in the regional condition $\left(\beta=0.55, \mathrm{SE}=.11, z=4.87^{* * *}\right)$, but not in the foreign accent condition $(\beta=0.2, \mathrm{SE}=.15, z=1.35)$. However, 'language background' is not a significant predictor when the predictor 'amount of regional accent experience' is added to the model. This shows that any descriptive differences between monolingual and bilingual children are in fact based on the amount of regional accent experience, not on language background.
} 
Table 4. Summary of Mixed Effect Logistic Regression in the Three Conditions

\begin{tabular}{|c|c|c|c|c|c|c|c|c|c|}
\hline Predictor & \multicolumn{9}{|c|}{ Condition } \\
\hline (Intercept) & -4.23 & .39 & $-10.89^{\star \star \star}$ & -0.85 & .21 & $-0.41^{\star \star \star}$ & -1.42 & .21 & $-6.64^{\star \star \star}$ \\
\hline Experience with regional accents & -0.8 & .38 & $-2.09^{\star}$ & -0.28 & .1 & $-2.94^{\star \star}$ & -0.1 & .14 & -0.71 \\
\hline Vocabulary mistakes & 0.11 & .24 & 0.43 & 0.15 & .07 & $2.24^{\star}$ & 0.2 & .12 & 1.65. \\
\hline Keyword frequency (log lemma frequency) & -0.31 & .12 & $-2.5^{*}$ & 0.09 & .05 & 1.66. & -0.21 & .06 & $-3.58^{\star \star \star}$ \\
\hline Experience regional * experience foreign & -0.18 & .52 & -0.36 & -0.09 & .12 & -0.76 & 0.22 & .17 & 1.3 \\
\hline Experience regional * experience other languages & -0.26 & .6 & -0.44 & 0.16 & .14 & 1.15 & -0.09 & .2 & -0.47 \\
\hline
\end{tabular}

Notes. ${ }^{* \star *} p<.001,{ }^{* *} p<.01,{ }^{*} p<.05, . p<0.1$. Negative estimates correspond to lower predicted probabilities for error rates. Formula: mistakes $\sim$ experience_regional ${ }^{*}$ experience_foreign ${ }^{\star}$ experience_other_languages + vocabulary_mistakes + frequency + (1| subject $)+(1+$ vocabulary_mistakes $\mid$ sentence) . 
Furthermore, to assess whether experience leading up to this point in time developmentally plays a role, we conducted an additional analysis with PERCENTAGE OF REGIONAL ACCENTS HEARD AT THE AGE FROM 0 TO 3. Experience with regional accents at that age was not significant and a superfluous predictor (anova model comparisons), so we excluded this predictor. The same kind of analysis was performed with the predictor EXPERIENCE WITH OTHER LANGUAGES AT AGE 0 TO 3, which also yielded insignificant results.

\section{Other factors}

There was an effect of vocabulary size in the regional accent condition, and only a trend in the foreign accent condition. Including vocabulary size in the models did not change the direction or significance of any of the other effects. Even though children showed ceiling performance in the standard condition, the fact that experience with regional accents improved performance in this condition might reveal something about proficiency. We used vocabulary size as an indication of German proficiency and tested whether children's proficiency can be predicted by amount of experience with regional-accented speech. Tao and Taft (2016) argue that differences in vocabulary between monolingual and bilingual speakers may lead to weaker comprehension performance in bilingual children, particularly when nonsense sentences are used. The correlation (Pearson) between children's EXPERIENCE WITH REGIONAL ACCENTS and VOCABULARY MISTAKES was significant $(r=-0.42, p<.001)$. Thus, children who had more experience with regional accents (mainly monolingual children) made fewer mistakes at the vocabulary test. The correlation between experience with foreign accents and vocabulary mistakes was not significant $(r=0.24, p=.06)$.

We also found that children who performed well in one accent performed well in another accent: regional and foreign accents $(r=0.42, p<.001)$, standard and regional accents $(r=0.42, p<.001)$, and standard and foreign accents $(r=0.27, p<.05)$.

In addition, lexical frequency of the keywords also had an effect on processing, with high-frequency keywords being more intelligible than low-frequency words in the standard and foreign condition, and with a trend in the opposite direction only in the regional condition.

\section{Discussion}

We tested primary school-aged children on the repetition of auditory utterances to examine how experience with accented speech impacts processing of Standard German and two unfamiliar accents (regional and foreign). More specifically, we assessed how type and amount of accent experience and the children's language backgrounds (monolingual and bilingual measured in amount of experience with other languages) modulate processing ease. The main finding in regard to experience with accents was that experience with regional accents led to a processing advantage in the regional accent condition as well as in the Standard German control condition. Thus, a child who regularly hears regional-accented German may have an advantage in processing an unfamiliar regional German accent as compared to a child who hears less regional-accented speech. However, experience with foreign accents did not help in any of the conditions. Moreover, there were no processing disadvantages for children who are exposed to a large amount of variability (i.e., regional and foreign accents as well as other languages). Importantly, there was no 
effect of experience with other languages in any of the conditions, suggesting comparable performance for both monolinguals and bilinguals. Despite a descriptive difference between monolingual and bilingual children in the standard and regional accent condition, the model results show that accent experience, not language background, had a significant effect on intelligibility.

This is not the first study to show comparable results for monolingual and bilingual children. Evans and Lourido (in press) found that while five- to six-year-old bilinguals outperform their monolingual peers at accent categorization, they showed no difference in comprehension of unfamiliar accents. However, we do find that vocabulary skills positively modulate comprehension performance. Additional correlational analyses revealed this effect to be driven by children with regional exposure, hence mainly monolingual children. Many previous studies have shown that vocabulary size in bilingual children tends to be smaller than for their monolingual peers, especially when testing occurs in one language only (Bialystok et al., 2010). This was the case in our study too (see Table 2). Participants with smaller vocabularies usually exhibit poorer performance than participants with larger vocabularies (e.g., Tao \& Taft, 2016). Tao and Taft argue that such performance differences are related to better vocabulary skills in monolingual compared to bilingual speakers, particularly when nonsense sentences are used. Similarly, monolinguals perform better at single-language word recognition tasks, potentially due to their larger vocabulary and the stability of their representations as a result of more frequent exposure (Bosch \& Sebastián-Gallés, 2003; Metsala \& Walley, 1998; Ramon-Casas et al., 2009). Notwithstanding this, we did not find a difference between monolingual and bilingual children's performance. Instead, we found an influence of vocabulary size on performance (in line with McDonald, Gross, Buac, Batko, \& Kaushanskaya, 2017), which correlates with children's language background and shows that several bilingual children also performed well in the vocabulary test.

Previous studies were inconclusive with respect to how experience helps process unfamiliar accents. While some studies reported benefits of experience (Baese-Berk et al., 2013; Bent \& Bradlow, 2003), others found no effect of experience (Tao \& Taft, 2016), and one study suggested disadvantages (Durrant et al., 2015). Our study shows clear benefits of experience with regional varieties and no effect of experience with foreign-accented varieties, suggesting that it may be important to distinguish between different types of accents and varieties. It remains an open question how these different types and amounts of exposure to variability affect lexical representations and impacts processing. According to Durrant et al., the lexical representations formed by children who grow up with a lot of variability due to different languages and accents might be less stable than those formed by children who are exposed to less variability (see also Creel, 2014). Following these studies, children with less experience with accented speech were expected to perform better than those with more experience. The benefit of experience with regional accents in our study, however, suggests that variability in the input may lead to a more flexible mapping of accented word forms onto stored representations. This is in line with some previous studies suggesting that exposure to multiple accents benefits understanding of novel accents (Baese-Berk et al., 2013; Clopper, 2014), and that this benefit is already present in infancy (Potter \& Saffran, 2017). Lexical representations in children with more accent experience might not be as fixed as in children with less accent experience. As pointed out by Van Heugten and Johnson (2017), less fixed representations might also lead to higher flexibility in the word recognition of 
older children with multi-accent input, resulting in benefits when processing an unfamiliar accent. Children with a lot of accent experience possibly store a wider range of exemplars and information about how words in accented speech may sound. In our study, this might have led to an advantage for finding common features between regional German accents (from accented words they know and the unfamiliar accent they hear in the experiment), which helps them map the accented word to the correct lexical entry.

It still remains to be explained why we did not find benefits of foreign accent exposure. It seems unlikely that only some and not other accent variability affects lexical representations, but it would be reasonable to assume that type and degree of variability matters, and thus affects processing in distinct ways (e.g., Sumner \& Samuel, 2009). Our results for foreign accent experience are in line with Tao and Taft (2016), who found no benefit of experience with foreign accents for the comprehension of an unfamiliar foreign accent; however, this study tested adults and assessed how accent experience during childhood affects processing in adulthood. Tao and Taft (2016) argue that listeners might be trying and failing to interpret the unfamiliar foreign accent within the framework of the familiar foreign accent they hear from parents or relatives. Again, it would be reasonable to assume that this should apply to both foreign and regional accent experience. It remains an open question whether children who have experience with regional accents are possibly more flexible in mapping unfamiliar pronunciation variants onto lexical representations than children who have experience with foreign accents.

A likely reason why foreign accent experience did not improve performance in our study is that the foreign accents children were familiar with and the unfamiliar accent in the experiment were more dissimilar than the regional accents (Pinet et al., 2011; Stringer 2015). Stringer argues that similarity between the accent of a talker and the accent of a listener could be a better predictor of accent intelligibility than familiarity or experience with accented speech. Stringer used a speech-in-noise recognition task and measured event-related potentials while English and Spanish speakers listened to Standard Southern British English, Glaswegian English, and Spanish-accented English. Her results indicate that accent similarity in talker-listener pairings strongly contributes to accent intelligibility. This suggests that listeners attempt to interpret unfamiliarly accented speech by mapping it onto existing lexical representations. Greater similarity between an unfamiliar accent and a familiar accent thus leads to an easier mapping of accented words to phonological representations, and more dissimilar accents are likely to be less intelligible than more similar accents. It is possible that, at least at the segmental level, the regional Palatinate accent in our study is more similar to the familiar regional accent (Swabian) than the unfamiliar Korean accent is to the familiar foreign accents of the children. Since the children in our study had various language backgrounds, this issue would need to be addressed in future studies that include a comparison of all foreign accents familiar to the children.

Our results thus showed that only experience with regional accents was helpful, and only in the standard and regional condition. Although previous studies did not directly compare regional with foreign accent experience, the mixed results suggest that it would be worth further examination. In addition to experiential factors, however, further factors intrinsic to the distinct backgrounds and skills of children should be considered. Children with low vocabulary scores had greater problems with understanding the unfamiliar regional accent, and there was a trend in the foreign 
accent. This result is in line with McDonald et al. (2017), who showed that a smaller vocabulary makes it more difficult to understand unfamiliarly accented speech. Note that, despite adding vocabulary performance (as an approximate indicator of lexical proficiency) to the model as a predictor, the effect of accent experience persisted. We also found significant positive correlations between performance in the standard, regional, and foreign accent conditions. Similar results have been observed for adults (Bent et al., 2016). Bent et al. attribute these results to skills such as an improved ability to recover from phoneme distortions due to expanded phoneme categories, which listeners can use to recognize unfamiliarly accented words in different types of accents. However, the correlations do not assess experience and thus can only be interpreted in terms of performance. Further factors such as phonological processing skills may improve perception performance in unfamiliar accents. Bent and Atagi (2017) found that listeners with greater phonological awareness are better at mapping unfamiliar pronunciation variants to lexical representations, and that this skill helps them to process foreign-accented speech. These results suggest that further factors such as phonological awareness, vocabulary, and general linguistic performance might improve performance.

It is still unclear, however, how much experience is weighted in comparison to such other factors. While standard tests for memory or vocabulary exist, measuring experience is more challenging since it depends on how and at what point in time during development experience is assessed. Experience with multiple accents during early infancy may have different effects on adult comprehension than experience during adolescence. We examined children's current exposure to accents, but additional analyses that included the percentage of regional accents heard from ages from 0 to 3 did not yield any significant results, nor did children's experience with other languages at age 0 to 3 . It would be interesting to find out how exposure to accents during previous development contributes to unfamiliar accent perception. We already know from a study by Sebastián-Gallés, Echeverría, and Bosch (2005) that simultaneous Spanish-Catalan bilingual children show decrements in perceiving Catalan vowel contrasts (that are difficult for monolingual Spanish listeners) when compared to Catalan dominant early bilinguals. This suggests that exposure to different varieties at different points in time during language development may affect the stability of lexical representations. In line with this suggestion, van Heugten and Johnson (2017) also found decrements in word recognition when testing infants who were exposed to accent variation early in life. Van Heugten and Johnson reason, however, that children's experience with variation might have positive effects in later development. While infants exposed to accent variation had difficulties coping with the task (unfamiliar speakers and no context), older children with multiple accent input should show greater flexibility at comprehending unfamiliar accents than children who are exposed to only one accent. It would therefore be interesting to examine at what age accent experience begins to affect later performance, in order to answer the question whether exposure to variation in early life is weighted heavier than at a later point (see also Bent, 2018). Furthermore, the number of accents a child is exposed to might play a role. For a given period of time children whose input consists of many different accents would have greater experience with phonological variation than those exposed to one single accent. Potter and Saffran (2017) have shown that young children's recognition of unfamiliarly accented words benefits from short-term exposure to multiple varieties as compared to only two varieties. We did not include the number of accents children were exposed to in our 
measure of accent experience because most of the children were exposed to one regional accent (Swabian in all cases but three) in addition to Standard German. In the three cases where another regional accent than Swabian was spoken by one parent, the accent was closely related to Swabian (Allgäu dialect of German). All but two bilingual children's parents either spoke the same native language or only one parent spoke a language other than German.

Another finding of this study was that lexically frequent keywords improved intelligibility in the standard and foreign accent condition. Input frequency plays an important role for word recognition because a word that has been accessed more often will be accessed faster if heard again (Ellis, 2002). This can help listeners recover from perceived deviations of familiar word forms when processing words in an unfamiliar accent. When we looked at the Levenshtein distances between standard and accented words, we also analyzed whether they differed for frequent vs. infrequent words. Non-native speakers might hear and produce infrequent words less often than frequent words and find these words more difficult to pronounce. The distance between our non-native speaker's accented word forms and the standard pronunciation was indeed larger for infrequent words as compared to frequent words, making the frequent words more intelligible for the child listeners than the infrequent words in the foreign accent condition. For the regional accent speaker, we obtained a tendency in the opposite direction, which might be due to a different explanation. Our regional accent speaker differed more strongly from standard pronunciation in frequent words as compared to infrequent words, possibly due to hearing and pronouncing the frequent words more often in her own accent and in different pronunciation variants. Schertz and Ernestus (2014), for example, show that high-frequency words have more pronunciation variants than low-frequency words (also see Keating, 1998). This might have made the regional speaker's frequent words harder to understand for the children than the infrequent words. Fast and fluent native speech might lead to more reduction in frequent words as compared to infrequent words (Jurafsky, Bell, Gregory, \& Raymond, 2001; Pluymaekers, Ernestus, \& Baayen, 2005), and thus to more difficulties in the processing of frequent words. A non-native speaker, on the other hand, might have less exposure to varying pronunciation forms and first has to acquire sensitivity to word frequency. The slower foreign-accented speech is less reduced in frequent words and thus children show less difficulty in the processing of those words. This question, while partly discussed in studies on the reduction of frequent vs. infrequent words (e.g., Connine, Ranbom, \& Patterson, 2008) could be examined in future studies that specifically look at differences in regional and foreign accent productions of frequent and infrequent words and the consequences for listeners.

Taken together, our study extends the existing literature on accented speech processing by analyzing the age-group of eight- to eleven-year-olds. We did not compare children's perception of accented speech to adults, but potential differences would be expected to emerge from smaller vocabulary and incomplete phonological processing skills as well as from overall exposure to accent variability, which is presumably greater in most adults, e.g., due to wider social networks and greater mobility.

To conclude, the results of this study suggest that experience with accented speech can lead to an advantage in children's processing of an unfamiliar accent, but this seems to be restricted to experience with regional accents and to regional accent perception. Children who are exposed to regional accents in German are better able 
to understand unfamiliar German regional accents than children who hear less regional-accented speech. However, no evidence for a benefit of experience with foreign-accented speech was observed. Accent variation in the input (regional and standard) may lead to higher flexibility and thus to better processing of unfamiliar regional accents. Since German regional accents are commonly encountered, the ability to understand an unfamiliar regional accent is crucial, especially if children also speak another language and thus already have less German input than their monolingual peers.

Acknowledgements. This research was supported by the German Research Foundation (DFG), grant GRK DFG 1624 'Frequency effects in language'.

\section{References}

Adank, P., Evans, B., Stuart-Smith, J., \& Scotti, S. (2009). Comprehension of familiar and unfamiliar native accents under adverse listening conditions. Journal of Experimental Psychology: Human Perception and Performance, 35, 520-9.

Adank, P., Van Hout, R., \& van de Velde, H. (2007). An acoustic description of the vowels of northern and southern standard Dutch II: regional varieties. Journal of the Acoustical Society of America, 121(2), $1130-41$.

Algethami, G., Ingram, J., \& Nguyen, T. (2010). The interlanguage speech intelligibility benefit: the case of Arabic-accented English. In Proceedings of the 2nd Pronunciation in Second Language Learning and Teaching Conference (pp. 30-42).

Ammon, U. (2015). On the social forces that determine what is standard in a language-with a look at the norms of non-standard language varieties. Bulletin VALS-ASLA, 53-67.

Ammon, U., \& Loewer, U. (1977). Dialekt/Hochsprache-Kontrastiv: Schwäbisch. Düsseldorf: Schwann.

Baese-Berk, M. M., Bradlow, A. R., \& Wright, B. A. (2013). Accent-independent adaptation to foreign accented speech. Journal of the Acoustical Society of America, 133(3), 174-80.

Barr, D. J., Levy, R., Scheepers, C., \& Tily, H. J. (2013). Random effects structure for confirmatory hypothesis testing: keep it maximal. Journal of Memory and Language, 68(3), 255-78.

Barry, W. J. (1974), Language background and the perception of foreign accent. Journal of Phonetics, 2(1), 65-89.

Bates, D., Maechler, M., Bolker, B., \& Walker, S. (2017). Fitting Linear Mixed-Effects Models using lme4. Journal of Statistical Software, 67(1), 1-48.

Behrman, A., \& Akhund, A. (2013). The influence of semantic context on the perception of Spanish-accented American English. Journal of Speech, Language, and Hearing Research, 56(5), 1567-78.

Bent, T. (2014). Children's perception of foreign-accented words. Journal of Child Language, 41(6), 1334-55.

Bent, T. (2015). Development of perceptual flexibility. In The Scottish Consortium for ICPhS 2015 (Ed.), Proceedings of the 18th International Congress of Phonetic Sciences, Glasgow, UK, the University of Glasgow. Online <https://www.internationalphoneticassociation.org/icphs-proceedings/ICPhS2015/ Papers/ICPHS0705.pdf $>$.

Bent, T. (2018). Development of unfamiliar accent comprehension continues through adolescence. Journal of Child Language, 45(6), 1400-11.

Bent, T., \& Atagi, E. (2015). Children's perception of nonnative-accented sentences in noise and quiet. Journal of the Acoustical Society of America, 138, 3985-93.

Bent, T., \& Atagi, E. (2017). Perception of nonnative-accented sentences by 5- to 8-year-olds and adults: the role of phonological processing skills. Language and Speech, 60(1), 110-22.

Bent, T., Baese-Berk, M., Borrie, S. A., \& McKee, M. (2016). Individual differences in the perception of regional, nonnative, and disordered speech varieties. Journal of the Acoustical Society of America, 140(5), 3775-86.

Bent, T., \& Bradlow, A. R. (2003). The interlanguage speech intelligibility benefit. Journal of the Acoustical Society of America, 114(3), 1600-10.

Best, C. T., Tyler, M. D., \& Quann, C. A. (2009). Development of phonological constancy: toddlers' perception of native- and Jamaican-accented words. Psychological Science, 20, 539-42. 
Bialystok, E. (2001). Bilingualism in development: language, literacy, and cognition. Cambridge University Press.

Bialystok, E., Luk, G., Peets, K. F., \& Yang, S. (2010). Receptive vocabulary differences in monolingual and bilingual children. Bilingualism: Language and Cognition, 13(4), 525-31.

Bosch, L., \& Sebastián-Gallés, N. (2003). Simultaneous bilingualism and the perception of a language-specific vowel contrast in the first year of life. Language and Speech, 46, 217-43.

Bradlow, A., \& Bent, T. (2008). Perceptual adaptation to non-native speech. Cognition, 106(2), 707-29.

Cito (2015). Cito-Sprachtest Version 3. Digitale Sprachstandserhebung im Elementarbereich. CITO Deutschland GmbH. Online <http://www.cito-sprachtest.de/wp-content/uploads/2017/07/cito_ sprachtest_version_3.pdf>.

Clarke, C. M., \& Garrett, M. F. (2004). Rapid adaptation to foreign-accented English. Journal of the Acoustical Society of America, 116, 3647-58.

Clopper, C. G. (2014). Sound change in the individual: effects of exposure on cross-dialect speech processing. Laboratory Phonology, 5(1), 69-90.

Clopper, C. G., Pisoni, D. B., and Tierney, A. T. (2006). Effects of open-set and closed-set task demands on spoken word recognition. Journal of the American Academy of Audiology, 17, 331-49.

Connine, C. M., Ranbom, L. J., \& Patterson, D. J. (2008). Processing variant forms in spoken word recognition: the role of variant frequency. Attention, Perception, \& Psychophysics, 70(3), 403-11.

Creel, S. C. (2012). Phonological similarity and mutual exclusivity: on-line recognition of atypical pronunciations in 3-5-year-olds. Developmental Science, 15, 697-713.

Creel, S. C. (2014). Impossible to _gnore: word-form inconsistency slows preschool children's word-learning. Language Learning and Development, 10(1), 68-95.

Cristia, A., Seidl, A., Vaughn, C., Schmale, R, Bradlow, A., \& Floccia, C. (2012). Linguistic processing of accented speech across the life span. Frontiers in Psychology, 3, 479. https://doi.org/10.3389/fpsyg.2012. 00479

Davies, A. (2003). The native speaker: myth and reality (Bilingual Education and Bilingualism, 38). Clevedon: Multilingual Matters.

Davis, M. H., Johnsrude, I. S., Hervais-Adelman, A., Taylor, K., \& McGettigan, C. (2005). Lexical information drives perceptual learning of distorted speech: evidence from the comprehension of noise-vocoded sentences. Journal of Experimental Psychology: General, 134(2), 222-41.

Dewaele, J.-M. (2018). Why the dichotomy 'L1 versus LX user' is better than 'native versus non-native speaker'. Applied Linguistics, 39(2), 236-40.

Durrant, S., Delle Luche, C., Cattani, A., \& Floccia, C. (2015). Monodialectal and multidialectal infants' representation of familiar words. Journal of Child Language, 42(2), 447-65.

Ellis, N. C. (2002). Frequency effects in language processing: a review with implications for theories of implicit and explicit language acquisition. Studies in Second Language Acquisition, 24(2), 143-88.

Evans, B. G., \& Lourido, A. M. (in press). Effects of language background on the development of sociolinguistic awareness: the perception of accent variation in monolingual and multilingual 5-7 year old children. Phonetica.

Flege, J. E., Munro, M. J., \& Fox, R. A. (1994). Auditory and categorical effects on cross-language vowel perception. Journal of the Acoustical Society of America, 95(6), 3623-41.

Floccia, C., Butler, J., Girard, F., \& Goslin, J. (2009a). Categorization of regional and foreign accent in 5- to 7-year-old British children. International Journal of Behavioral Development, 33, 366-75.

Floccia, C., Butler, J., Goslin, J., \& Ellis, L. (2009b). Regional and foreign accent processing in English: Can listeners adapt? Journal of Psycholinguistic Research, 38(4), 379-412.

Floccia, C., Delle Luche, C., Durrant, S., Butler, J., \& Goslin, J. (2012). Parent or community: Where do 20-month-olds exposed to two accents acquire their representation of words? Cognition, 124(1), 95-100.

Floccia, C., Goslin, J., Girard, F., \& Konopczynski, G. (2006). Does a regional accent perturb speech processing? Journal of Experimental Psychology: Human Perception and Performance, 32(5), $1276-93$.

Grabe, E., Post, B., Nolan, F., \& Farrar, K. (2000). Pitch accent realization in four varieties of British English. Journal of Phonetics, 28(2), 161-85.

Grosjean, F. (2010). Bilingual: life and reality. Cambridge, MA: Harvard University Press.

Hanulíková, A., \& Weber, A. (2012). Sink positive: linguistic experience with th substitutions influences nonnative word recognition. Attention, Perception, \& Psychophysics, 74(3), 613-29. 
Harte, J., Oliveira, A., Frizelle, P., \& Gibbon, F. (2016). Children's comprehension of an unfamiliar speaker accent: a review. International Journal of Language \& Communication Disorders, 51(3), 221-35.

Heeringa, W. J. (2004). Measuring dialect pronunciation differences using Levenshtein distance. Unpublished doctoral dissertation, University Library Groningen.

Jacewicz, E., \& Fox, R. A. (2014). The effects of indexical and phonetic variation on vowel perception in typically developing 9- to 12-year-old children. Journal of Speech, Language, and Hearing Research, 57, 389-405.

Johnson, C. E. (2000). Children's phoneme identification in reverberation and noise. Journal of Speech, Language, and Hearing Research, 43, 144-57.

Jurafsky, D., Bell, A., Gregory, M., \& Raymond, W. D. (2001). Probabilistic relations between words: evidence from reduction in lexical production. Typological Studies in Language, 45, 229-54.

Keating, P. A. (1998). Word-level phonetic variation in large speech corpora. ZAS Papers in Linguistics, 11, $35-50$.

Kitamura, C., Panneton, R., \& Best, C. T. (2013). The development of language constancy: attention to native versus nonnative accents. Child Development, 84(5), 1686-700.

Kuznetsova, A., Brockhoff, P. B., \& Christensen, R. H. B. (2015). Package 'ImerTest'. R package version, 2.0. Online <http://cran.r-project.org/web/packages/lmerTest/index.html>.

Lalonde, K., \& Holt, R. F. (2016). Audiovisual speech perception development at varying levels of perceptual processing. Journal of the Acoustical Society of America, 139(4), 1713-23.

Leung, A.H.-C. (2012). Bad influence? - an investigation into the purported negative influence of foreign domestic helpers on children's second language English acquisition. Journal of Multilingual and Multicultural Development, 33(2), 133-48.

Levenshtein, V. I. (1966). Binary codes capable of correcting deletions, insertions, and reversals. Soviet Physics-Doklady, 10(8), 707-10.

Major, R. C., Fitzmaurice, S. F., Bunta, F., \& Balasubramanian, C. (2002). The effects of nonnative accents on listening comprehension: implications for ESL assessment. TESOL Quarterly, 36(2), 173-90.

Mathôt, S., Schreij, D., \& Theeuwes, J. (2012). OpenSesame: an open-source, graphical experiment builder for the social sciences. Behavior Research Methods, 44(2), 314-24.

Mattheier, K. J. (1990). Dialekt und Standardsprache. Über das Varietätensystem des Deutschen in der Bundesrepublik. International Journal of the Sociology of Language, 83, 59-82.

Maye, J., Aslin, R. N., \& Tanenhaus, M. K. (2008). The weckud wetch of the wast: lexical adaptation to a novel accent. Cognitive Science, 32(3), 543-62.

McDonald, M., Gross, M., Buac, M., Batko, M., \& Kaushanskaya, M. (2017). Processing and comprehension of accented speech by monolingual and bilingual children. Language Learning and Development, 14(2), 113-29.

McQueen, J. M., Tyler, M. D., \& Cutler, A. (2012). Lexical retuning of children's speech perception: evidence for knowledge about words' component sounds. Language Learning and Development, 8(4), 317-39.

Metsala, J. L., \& Walley, A. C. (1998). Spoken vocabulary growth and the segmental restructuring of lexical representations: precursors to phonemic awareness and early reading ability. In J. L. Metsala \& L. C. Ehri (Eds.), Word recognition in beginning literacy (pp. 89-120). Mahwah, NJ: Lawrence Erlbaum Associates.

Muench, K. (2011). Word learning under accent variability in monolinguals and bilinguals. 2010-2011 Unpublished Honors Project Language Acquisition and Sound Recognition, Department of Cognitive Science, University of California - San Diego.

Munro, M. J., \& Derwing, T. M. (1999). Foreign accent, comprehensibility, and intelligibility in the speech of second language learners. Language Learning, 49(1), 285-310.

Munro, M. J., Derwing, T. M., \& Morton, S. L. (2006). The mutual intelligibility of L2 speech. Studies in Second Language Acquisition, 28(1), 111-31.

Nathan, L., Wells, B., \& Donlan, C. (1998). Children's comprehension of unfamiliar regional accents: a preliminary investigation. Journal of Child Language, 25, 343-65.

Pettersson, E., Megyesi, B., \& Nivre, J. (2013). Normalisation of historical text using context-sensitive weighted Levenshtein distance and compound splitting. In Proceedings of the 19th Nordic Conference of Computational Linguistics (NODALIDA 2013), 22-24 May, 2013, Oslo University, Norway. NEALT Proceedings Series 16 (No. 085, pp. 163-79). Linköping University Electronic Press. Online <http:// www.ep.liu.se/ecp/contents.asp?issue $=085>$. 
Pinet, M., Iverson, P., \& Huckvale, M. (2011). Second-language experience and speech-in-noise recognition: effects of talker-listener accent similarity. Journal of the Acoustical Society of America, 130(3), 1653-62.

Pluymaekers, M., Ernestus, M., \& Baayen, R. H. (2005). Lexical frequency and acoustic reduction in spoken Dutch. Journal of the Acoustical Society of America, 18, 2561-9.

Porretta, V., Tucker, B., \& Järvikivi, J. (2016). The influence of gradient foreign accentedness and listener experience on word recognition. Journal of Phonetics, 58, 1-21.

Potter, C. E., \& Saffran, J. R. (2017). Exposure to multiple accents supports infants' understanding of novel accents. Cognition, 166, 67-72.

Ramon-Casas, M., Swingley, D., Sebastián-Gallés, N., \& Bosch, L. (2009). Vowel categorization during word recognition in bilingual toddlers. Cognitive Psychology, 59(1), 96-121.

R Core Team (2017). R: a language and environment for statistical computing. Online <https:/www.Rproject.org/>.

Reinisch, E., Weber, A., \& Mitterer, H. (2013). Listeners retune phoneme categories across languages. Journal of Experimental Psychology: Human Perception and Performance, 39(1), 75-86.

Rost, G. C., \& McMurray, B. (2009). Speaker variability augments phonological processing in early word learning. Developmental Science, 12(2), 339-49.

Samuel, A. G., \& Larraza, S. (2015). Does listening to non-native speech impair speech perception? Journal of Memory and Language, 81, 51-71.

Schäfer, P. (2016). Decibel Ultra (decibel meter for iPhones). Online <https://itunes.apple.com/us/app/ decibel-ultra/id410139517? $\mathrm{mt}=8>$.

Schertz, J., \& Ernestus, M. (2014). Variability in the pronunciation of non-native English the: effects of frequency and disfluencies. Corpus Linguistics and Linguistic Theory, 10(2), 329-45.

Schmale, R., Cristia, A., \& Seidl, A. (2012). Toddlers recognize words in an unfamiliar accent after brief exposure. Developmental Science, 15(6), 732-38.

Schmale, R., Hollich, G., \& Seidl, A. (2011). Contending with foreign accent in early word learning. Journal of Child Language, 38(5), 1096-108.

Schöler, H., \& Brunner, M. (2008). HASE Heidelberger Auditives Screening in der Einschulungsuntersuchung (2nd ed.). Göttingen: Hogrefe.

Schroeder, S., Würzner, K.-M., Heister, J., Geyken, A., \& Kliegl, R. (2015). childLex: a lexical database of German read by children. Behavior Research Methods, 47, 1085-94.

Sebastián-Gallés, N., Echeverría, S., \& Bosch, L. (2005). The influence of initial exposure on lexical representation: comparing early and simultaneous bilinguals. Journal of Memory and Language, 52(2), $240-55$.

Sereno, J., Lammers, L., \& Jongman, A. (2016). The relative contribution of segments and intonation to the perception of foreign-accented speech. Applied Psycholinguistics, 37(2), 303-22.

Sidaras, S. K., Alexander, J. E. D., \& Nygaard, L. C. (2009). Perceptual learning of systematic variation in Spanish-accented speech. Journal of the Acoustical Society of America, 125, 3306-16.

Stibbard, R. M., \& Lee, J. I. (2006). Evidence against the mismatched interlanguage speech intelligibility benefit hypothesis. Journal of the Acoustical Society of America, 120(1), 433-42.

Stringer, L. M. (2015). Accent intelligibility across native and non-native accent pairings: investigating links with electrophysiological measures of word recognition. Unpublished doctoral dissertation, University College London.

Sumner, M., \& Samuel, A. (2009). The effect of experience on the perception and representation of dialect variants. Journal of Memory and Language, 60, 487-501.

Tao, L., \& Taft, M. (2016). Effects of early home language environment on perception and production of speech. Bilingualism: Language and Cognition, 20(5), 1030-44.

Truckenbrodt, H. (2002). Upstep and embedded register levels. Phonology, 19(1), 77-120.

Van Heugten, M., \& Johnson, E. K. (2014). Learning to contend with accents in infancy: benefits of brief speaker exposure. Journal of Experimental Psychology, 143(1), 340-50.

Van Heugten, M., \& Johnson, E. K. (2017). Input matters: multi-accent language exposure affects word form recognition in infancy. Journal of the Acoustical Society of America, 142(2), 196-200.

Wells, J. C. (1982). Accents of English (Vol. 1). Cambridge University Press.

Witteman, M. J., Weber, A., \& McQueen, J. M. (2013). Tolerance for inconsistency in foreign-accented speech. Psychonomic Bulletin \& Review, 21, 512-19. 


\section{Appendix}

Sentences used in the sentence repetition task

\section{List 1}

\begin{tabular}{ll}
\hline German sentence & \multicolumn{1}{c}{ English translation } \\
\hline Der alte Helm angelt. & The old helmet is fishing. \\
\hline Im Schraubenzieher liegt eine Ente. & There is a duck lying in the screwdriver. \\
\hline Die neue Giraffe bezahlt im Schwimmbad. & The new giraffe pays in the swimming pool. \\
\hline Die Mutter steigt auf den verdoppelten Tag. & The mother climbs onto the double day. \\
\hline Die dunkle Tür ist zubereitet. & The dark door is cooked. \\
\hline Das schreiende Herz schläft. & The screaming heart is sleeping. \\
\hline Morgen trinkt der Tisch einen Baum. & Tomorrow, the table will drink a tree. \\
\hline Das Buch hängt im Auto. & The book is hanging in the car. \\
\hline Der Freund fällt auf das Schiff. & The friend is falling onto the ship. \\
\hline Ein schnüffelnder Graben blubbert. & A sniffing ditch is bubbling. \\
\hline Eine seltsame Ampel strickt. & A strange traffic light is knitting. \\
\hline Das Kabel betrachtet den Anzug. & The cable looks at the suit. \\
\hline
\end{tabular}

\section{List 2}

\begin{tabular}{ll}
\hline German sentence & \multicolumn{1}{c}{ English translation } \\
\hline Ein rutschiges Stockwerk ist langsam. & A slippery floor is slow. \\
\hline Das rote Fohlen prüft den Kasten. & The red foal tests the box. \\
\hline Ein Koch spielt mit einer Ameise. & A cook is playing with an ant. \\
\hline Ein Finger heiratet einen Kindergarten. & A finger marries a kindergarten. \\
\hline Ein Zebra klettert über ein Mädchen. & A zebra climbs over a girl. \\
\hline Die große Tasse lobt das Meer. & The big cup praises the sea. \\
\hline Ein König zeigt auf die Schule. & A king is pointing to the school. \\
\hline Das wütende Pferd schreibt grün. & The angry horse is writing in green. \\
\hline Der Abend schüttelt den Stift. & The evening is shaking the pen. \\
\hline Der Esel wirkt stachelig. & The donkey seems prickly. \\
\hline Der sonnige Goldfisch ist klebrig. & The sunny goldfish is sticky. \\
\hline Ein weinendes Fass verbrennt eine Gabel. & A crying barrel is burning a fork. \\
\hline
\end{tabular}


List 3

\begin{tabular}{ll}
\hline German sentence & \multicolumn{1}{c}{ English translation } \\
\hline $\begin{array}{l}\text { Der würzige Hammer steht auf dem } \\
\text { Strauß. }\end{array}$ & The seasoned hammer is standing on the bouquet. \\
\hline Ein starker Zopf grüßt. & A strong braid salutes. \\
\hline Der Sänger schaukelt im Himmel. & A singer swings in heaven. \\
\hline Der Bauch hört den Verkäufer. & The belly is listening to the salesperson. \\
\hline Drei Handschuhe schieben einen Ballon. & Three gloves are pushing a balloon. \\
\hline Die blaue Katze redet. & The blue cat is talking. \\
\hline Die essende Treppe ist warm. & The munching stairs are warm. \\
\hline Das Bild gibt dem Jungen einen Stuhl. & The picture gives the boy a chair. \\
\hline Die Berge verstehen den Lehrer. & The mountains understand the teacher. \\
\hline Die Pfanne trommelt auf der Wurst. & The pan is drumming on the sausage. \\
\hline Eine Ziege gräbt in der Dusche. & A goat is digging in the shower. \\
\hline
\end{tabular}

Cite this article: Levy H, Konieczny L, Hanulíková A (2019). Processing of unfamiliar accents in monolingual and bilingual children: effects of type and amount of accent experience. Journal of Child Language 46, 368-392. https://doi.org/10.1017/S030500091800051X 